\title{
العربية في الكلمات التعبيري وتعريب الدخيل
}

\author{
Abdul Ghofur \\ IAI KH. Abdul Chalim Pacet Mojokerto \\ (abuthiobah@gmail.com)
}

\begin{abstract}
This topic, based on the claim, that reaching the goals of obtaining the flag in particular the Arabic language from the breadth of language. It is also known that the spread of Arabic in the expression (tandem and common verbal and antibodies) and the Arabization of the intruder there are the opinions of scientists in the phenomenon of occurrence in the language, some of them said the occurrence in the language, some of whom denied the occurrence. Based on this, the objectives of this research are: To learn about the breadth of Arabic in the expression (tandem and joint verbal and antibodies) and Arabization of the intruder, and to know the views of scientists in the phenomenon of Asa in this expression.
\end{abstract}

Keywords: Arabic language, language, expression

\section{تمهييد}

الحمد الله الذي خلق الإنسان ذا ميزة باللسان، والصلاة والسلام على محمد المبعوث إلى سائر الإنسان والجان، وعلى آله وأصحابه الطاهرين والفائزين بالرضوان، ديره بالهان وعلى التابعين

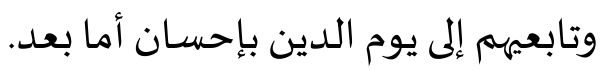

حين نصف العربية بسعة التعبير، وكثرة المفردات، وتنوع الدلالات، وحين نتجرأ أكثر من

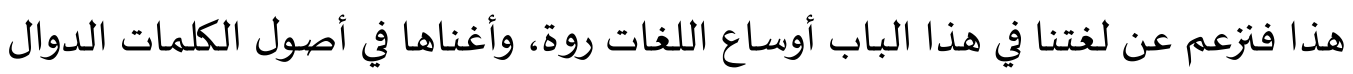


على معان متشعباة، قديمة وحديثة- جديرا بنا أن نذكر أن اللغات جميعا، دون استثناء،

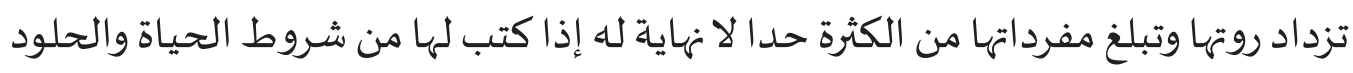

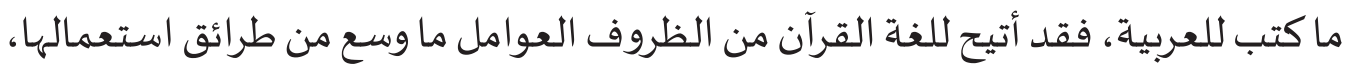
وأساليب اشتقاقها، وتنوع لهجاتها، فانطوت من هذا كله على محصول اتئهر لغوي. في هذه المرة أرادت الباحثة أن تبحث عن شيئ يتعلق بفقاه اللغة وعلوهها عن اتساع العربية

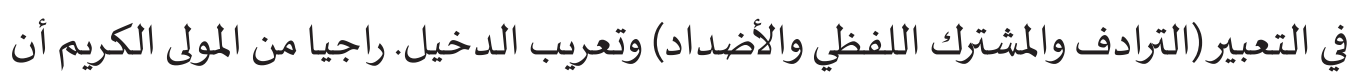
يعلمنا ما لم نكن نعلم.

\section{ا. اتساع العربية في التعبير ( الترادف و المشترك اللفظي و الأضيداد )

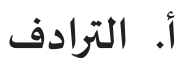

\section{1. مفهوم الترادف}

من منابع إثراء اللغةة، يراد باه دلالة لفظين أو أكثر على معنى واحد, فهو بذا عكس الاشتراك

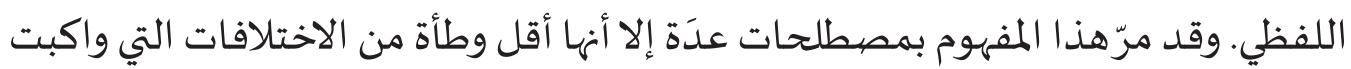

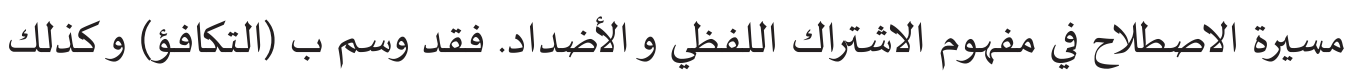

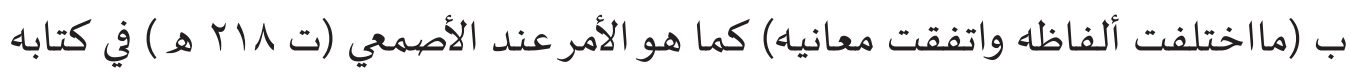

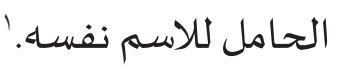

الترادف لغة: التتابع. الترادف اصطلاحا: دلالة عدد من الكلمات المختلفة على معنى واحد.

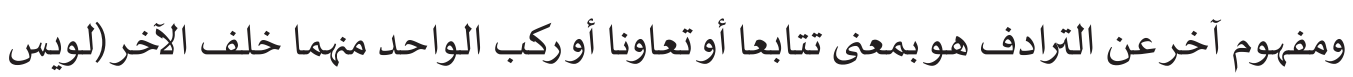

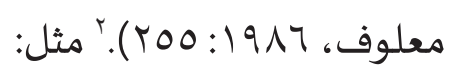
أ. الجود، والسخاء، والأريحية، والندى، والسماحة، والكرم، والبذل. ت. ت. عأيت الشيء، وأبصرته، وعاينته، وشـاهدته. 
أما الترادف في الإصطلاح، فليس فيه اتفاق بين العلماء والباحثين قديما وحديثا، وأنهم اختلفوا في تعريفه وتحديد عناصره. وجدير بالذكر ، أن العلماء الأوائل لم يعرفوا مصطلاح

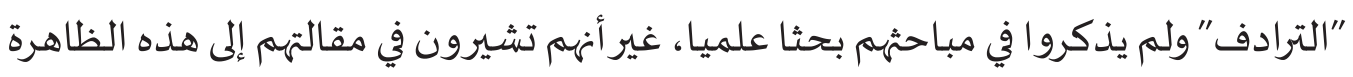

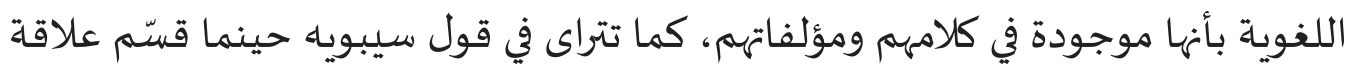

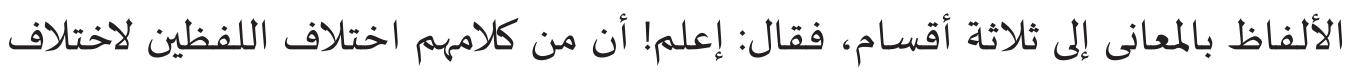

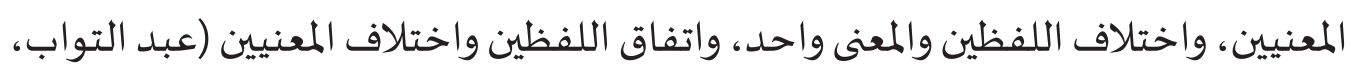

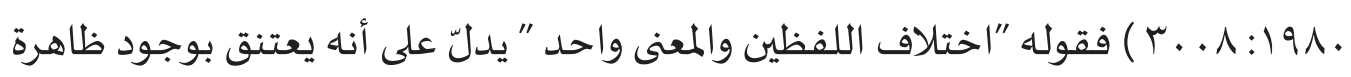
لغوية معروفة اليوم بالترادف. إختوله

خلاصة القول أنّ الترادف لغة: التتابع. الترادف اصطلاحا: دلالة عدد من الكلمات المختلفة على معنى واحد. الترادف ظاهرة من ظواهر اللغة، يشتغل باء كثيرا من الدارسين قديما وحديثا، وقد اختلف اللغويون في تعريف الترادف في اللغة العربية، وفقا على هذا، فإنهم اختلفوا في كيانه فيها.

r. الاختلاف حول وجود الترادف في اللغة اختلف اللغويون قديما وحديثا حول حقيقة وجود الترادف في اللغة بين مثبت ومنكر . وفي إنكارهم معنى أخطر كثيرا مما يصوره أي باحث من المحدثين، فلا سبيل معاه إلى القول بانفراد العربية بكثرة المفردات وسعة التعبير.

ب. الاشتراك في اللفظ:

أي أن المعاني متعددة، أي أن "المصباديق" متعددة -المصاديق جمع مصيداق ما يصدق عليه

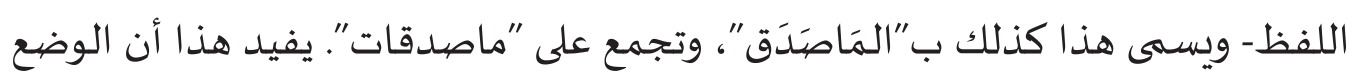

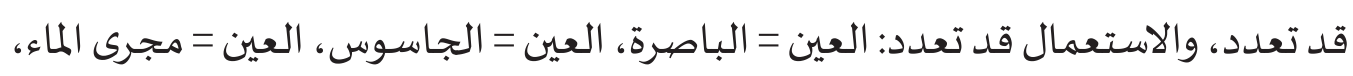

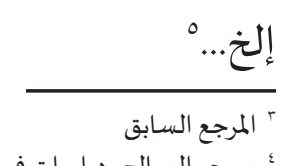

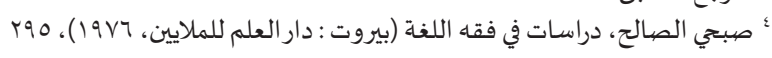


المشترك اللفظي اصطلاحًا بينما يذهب تاجُ الدين السبكيُّ إلى أنه ”اللفظ الواحد، الدالُّ

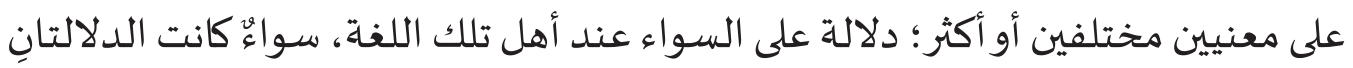

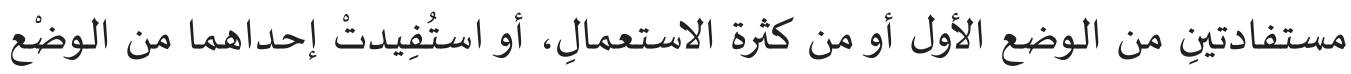

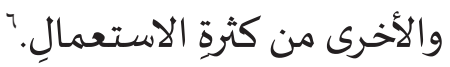

معنى اخر أن الاشتراك اللفظي هو أن تتطابق كلمتان أو أكثرفي اللفظ وتختلفان في المعنى أو

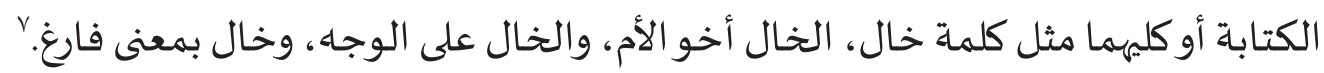

\section{1. طبيعة الاشتراك اللفظي}

يفرق بعض علماء اللغة المعاصرين من حيث المفهوم بين الاشتراك اللفظي ، أو ما يسمونـا

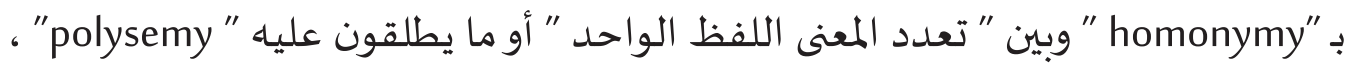
وينظرون إلههما على أنهما موضوعان مستقلان ، يتناول أولهما - كما يستفاد من كتاباتهم أو

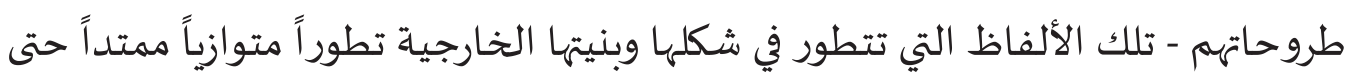

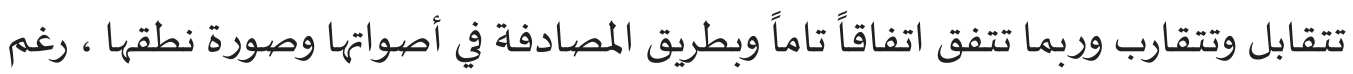
اختلاف معانيها وصورة كتابتها ، كما في الكلمتين الإنكليزيتين: see التي تعني بالعربية (يرى)

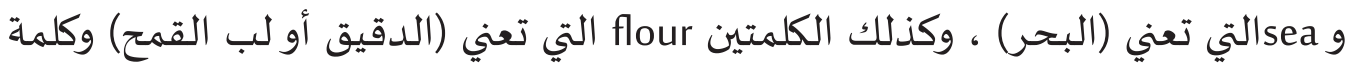
flower

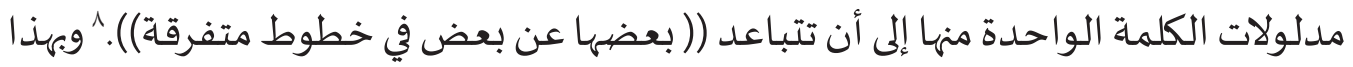

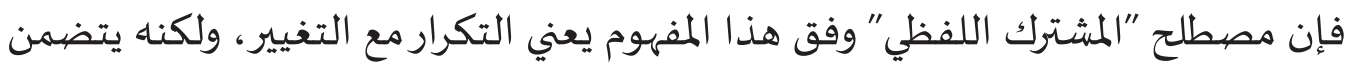

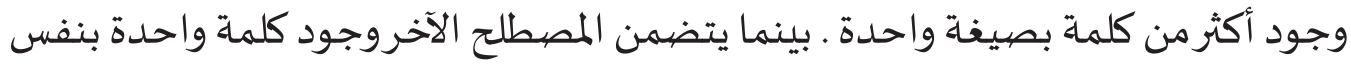

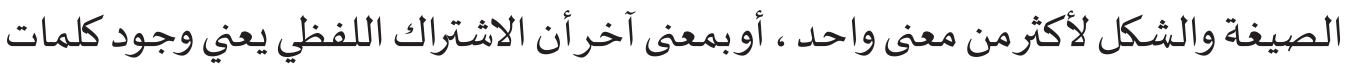

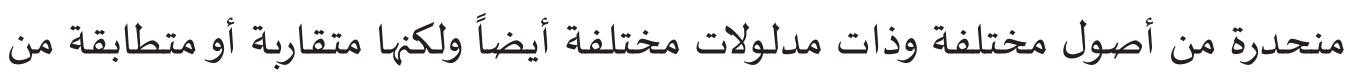

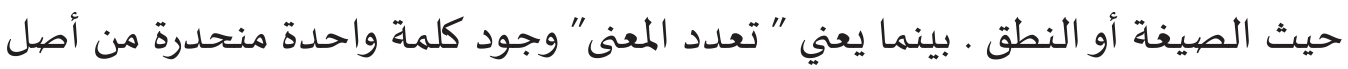

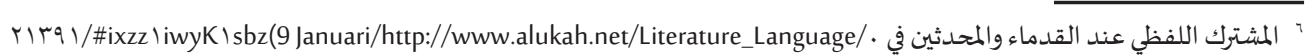


في بعض اللغات يكون الاشتراك اللفظي بكلمات تتطابق لفظا وتختلف كتابة ومعنى. مثل right (صواب)، write (يكتب)، (طقس من الطقوس). كما يكون الاشتراك اللفظي

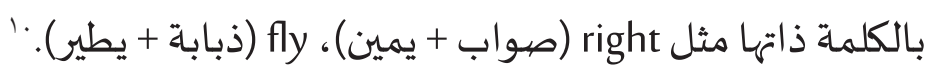

تدعى الكلمة ذات الاشتراك اللفظي مشتركا لفظيا. وبعض العلماء ينكروجود هذه المشركات

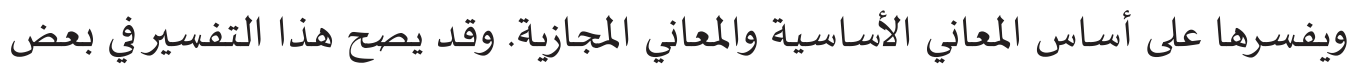

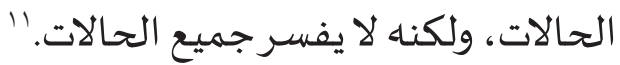

خلاصة القول أن الاشتراك اللفظي هو أن تتطابق كلمتان أو أكثر في اللفظ وتختلفان في المعنى أو الكتابة أو كليهما.

r. آراء العلماء فى ظاهرة المشترك اللفظى:

اختلفت آراء علماءنا القدامى فى وجوب، أو جواز، أو منع وقوع المشترك اللفظى فى اللغة، فمنهم من قال بوقوعاه في اللغة، ومنهم من أنكروقوعـه فيها. أ- القائلون بوقوعه في اللغة: والقائلون بوقوعه في اللغة منهم من أوجباه، ومنهم من أجازه: 1. ذذهب بعض العلماء إلى أنها واجب الوقوع فى اللغة، وحجتهم "أن الألفاظ متناهية،

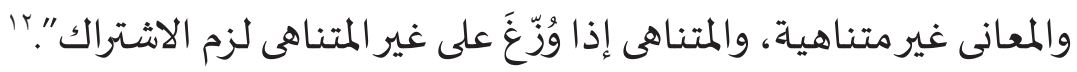

r. وذهب كثير من العلماء المتقدمين إلى القول بأنه ممكن الوقوع، من هؤلاء: سيبوياه،

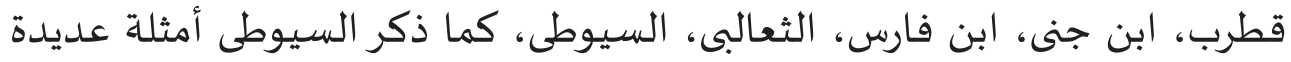

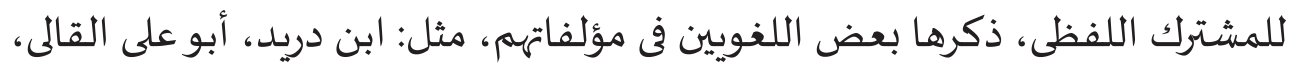

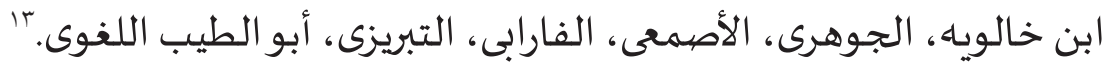

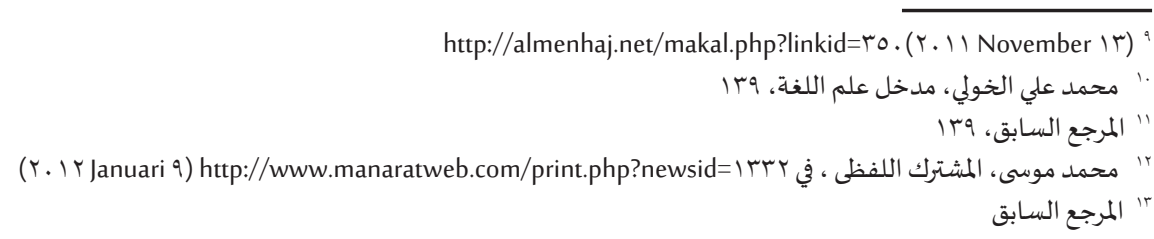


أنكر ابن درستويه في كتابه (شرح الفصيح)؛' وقوع المشترك اللفظى فى اللغة من واضع

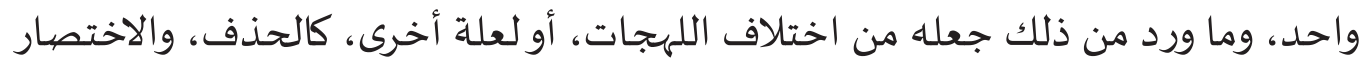

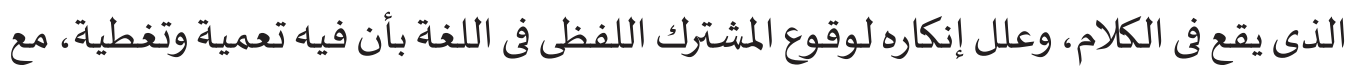
أن اللغة موضوعة للإبانة عما في النفس.

وممن أنكر المشترك اللفظى - كذلك - أبوزيد البلخى (ت ب Tr هـ)، ومحمد بن عبد الله الأبهرى (ت MVO هـ)، وعلة ذلك عندهما أن وقوع المشترك فى اللغة "يقتضى المفسدة، لأن المقصيود من الألفاظ ووضعها، إنما هو التفاهم حالة التخاطب، والمشترك لو وقع وسمعاه السـامع

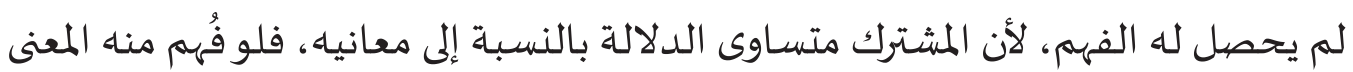

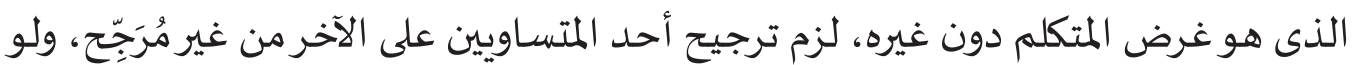
فُهم غيره لأدى إلى وقوع المفسـدة".

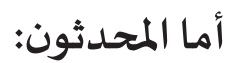

منهم من انتصر لوقوع المشترك اللفظى فى اللغة، وهو صببحى الصالح، حيث أخذ يلتمس

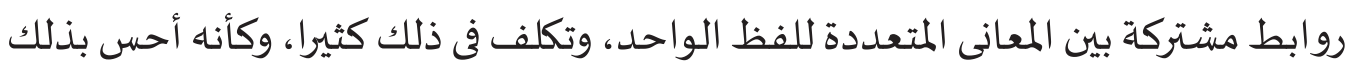
عندما قال: "ولقد يكون فى التماس هذه الروابط المشتركة بعض التكلف، ولكنها يظل خيرًا

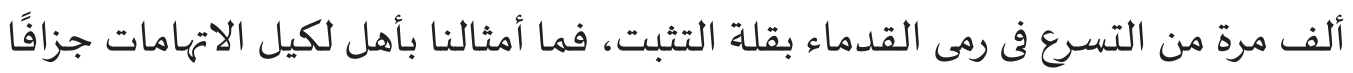

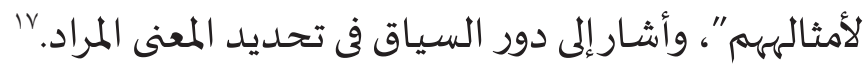
ومن المحدثين من وقف أمام ظاهرة المشترك اللفظى موقف المتشدد، فأخرج منه كل

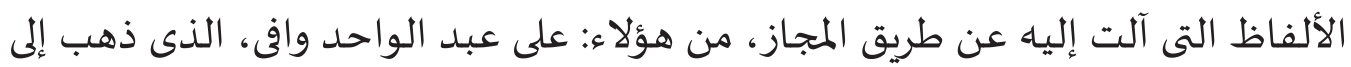

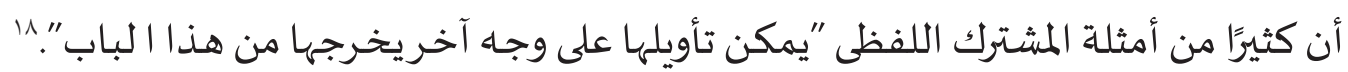

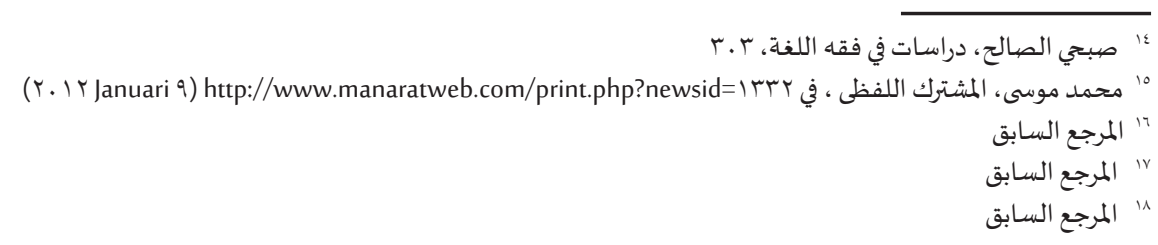


كما ذهب إبراهيم أنيس إلى نفس المذهب فقال: "إذا اتضح أن أحد المعنيين هو الأصل،

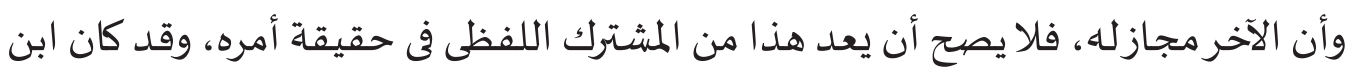

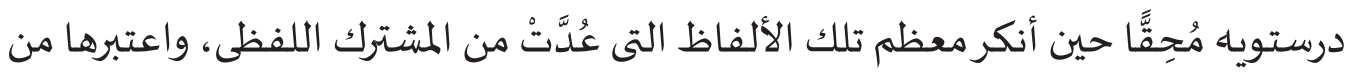

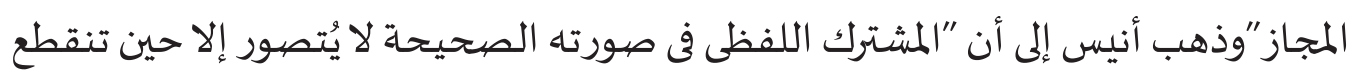

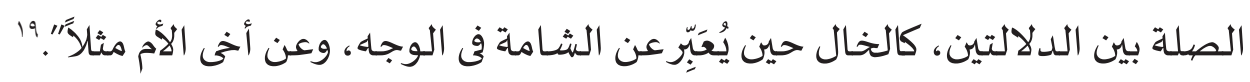

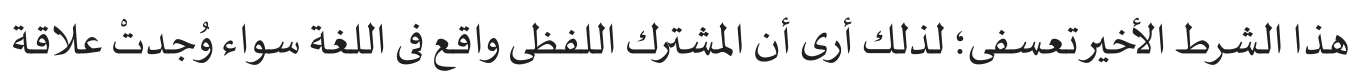

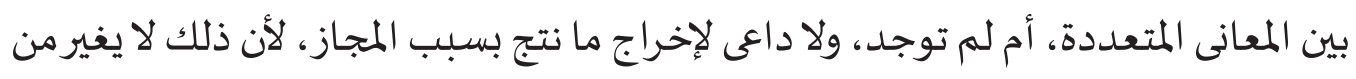

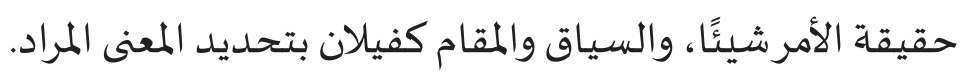

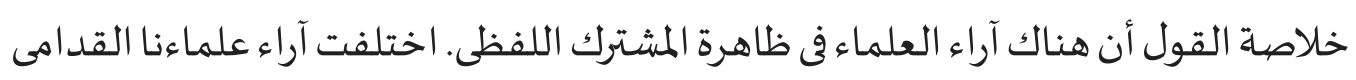

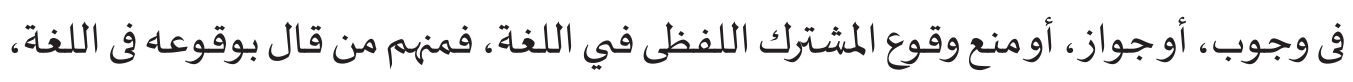

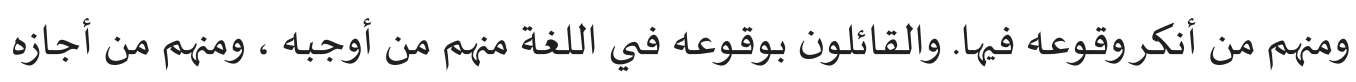

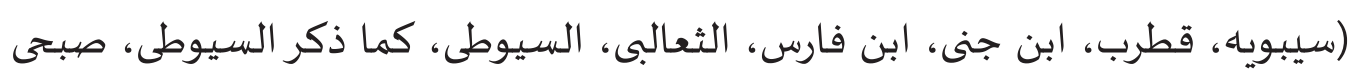

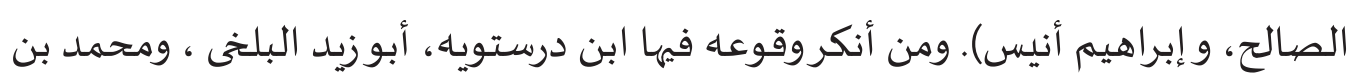
عبد الله الأهرى. - وايراهي

\section{ت. الأضداد}

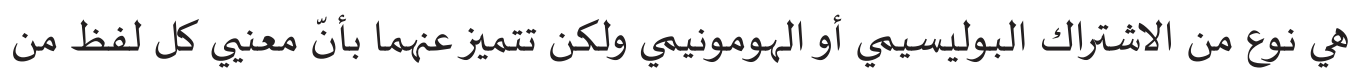

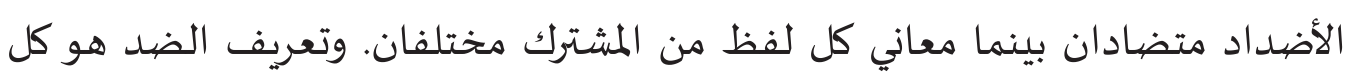

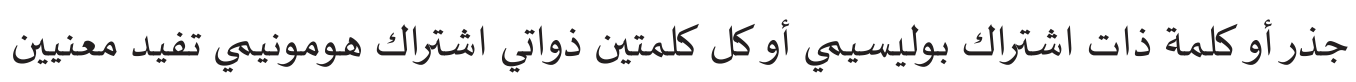

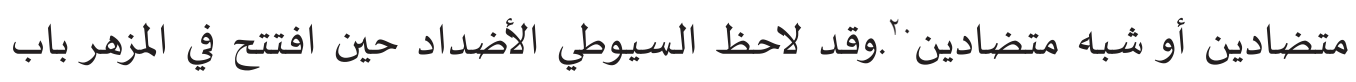

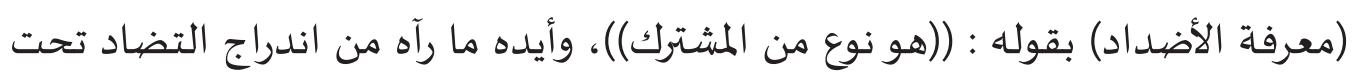

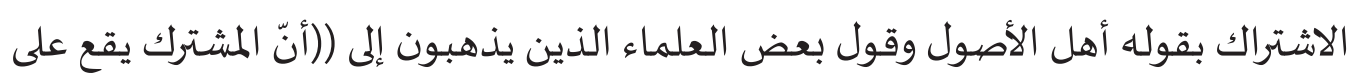

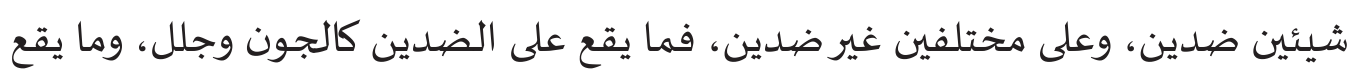


على مختلفين غير ضيدين كالعين)).

الأضيداد ظاهرة من الظواهر اللغوية التي أسهمت في نموّ الثروة اللفظية والإتساع في التعبير

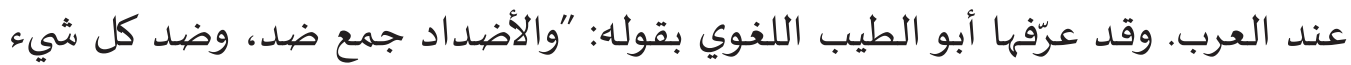

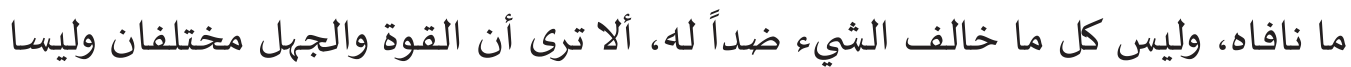
ضدين، وإنما ضهد القوة الضعف، وضيد الجهل العلم". وعرّفها ابن فارس الرازي بقوله:

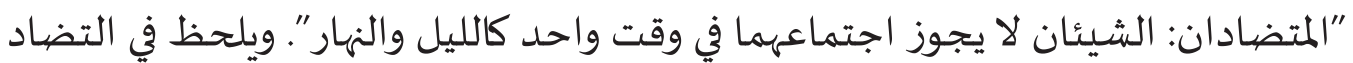

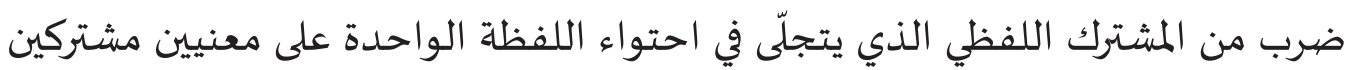

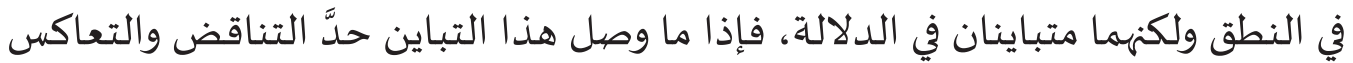
عُدَّت اللفظة في الأضيداد. واللغويون الذين سلكوا التضياد في جملة المشترك اللفظي نصيّوا

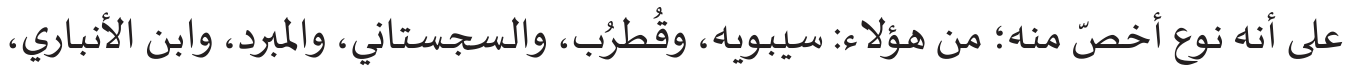

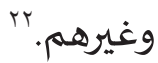

من أمثلة التضياد: السُّدْفة، تـدل على الظلمة وعلى الضيوء، والصريم: الليل والنهار، والصهارخ:

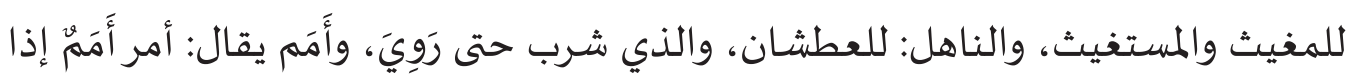

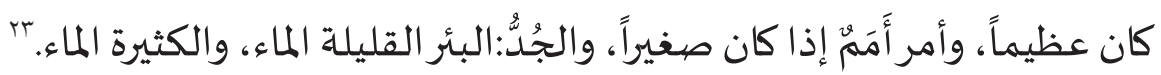

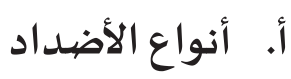

1. التضاد المتدرج : مثل ساخن، حار، دافئ، معتدل، بارد، مثلج، متجمد. r. التضاد الحاد أوغير متدرج : مثل ذكروأنثى، أعزب ومتزوج، حي وميتراسب وناجح. وهي

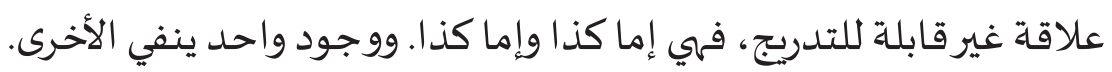

r. التضياد العكسي : مثل يبيع ويشتري، بيع وشراء، بائع ومشتري. ع. التضياد الاتجاهي : مثل فوق وتحت، علوي وسفلي، شمال وجنوب. گُ

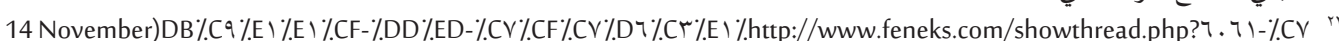

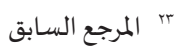

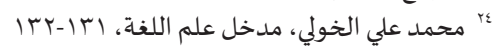




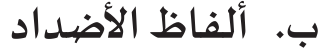

قائمة مختارة من كتاب المزهر في علوم اللغة للسيوطي :

ا. النَّاهِل في كلام العرب: العَطْشَان والناهل: الذي قد شرِب حتى رَوي.

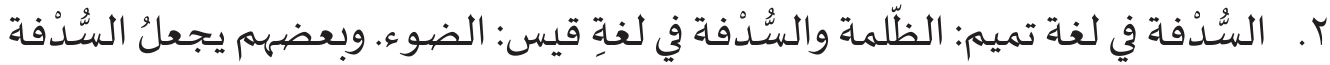
اختلاطُ الضهوء والظلمة معاً. كوقتِ ما بين صلاة الفجر إلى الإسفار.

r. وقال أبوزيد: طلَعتَ على القوم أطلع طلوعاً إذا غبتَ عنهم حتى لا يروك وطلَعت عليهم إذا أقبلتَ عليهم حتى يَرَوْك.

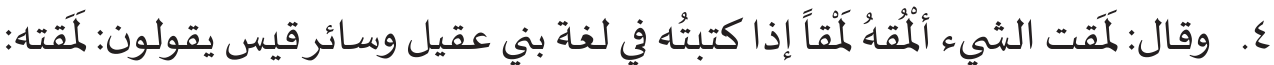
ro مَحَوْتَه.

ألا ترى أنّ الأضيداد جمع ضيد، وضيد كل شيء ما نافاه، وليس كل ما خالف الشيء ضيداً له ، وأن القوة والجهل مختلفان وليسا ضيدين، وإنما ضيد القوة الضعف، وضهد الجهل العلم. خلاصحة القول أنّ أنواع هناك الأضيداد منها التضياد المتدرج، التضياد الحاد أو غير متدرج ، التضياد العكسي والتضاد الاتجاهي.

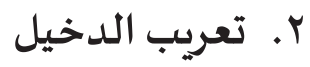

التعريب في اللغة : والتعريب في اللغة من عرّب الأسم الاعجمي , أي صيره عربياً هو ما

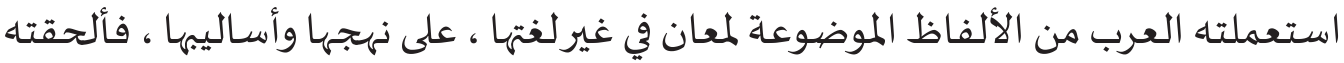

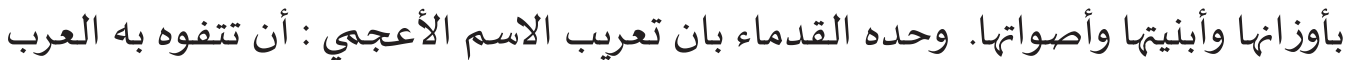

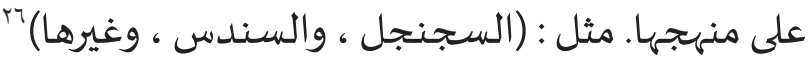

أما الدخيل: فهو الهجين والغريب، والذي لا يمتّ بصلة في أي من جوانباه إلى اللغة العربية،

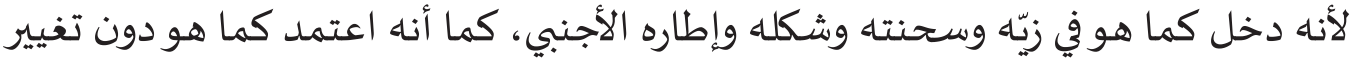
وتبديل وإضيافة وحذف من قبل مجامع اللغة العربية، وموافقة اللغويين العرب. lisan/fiqhlughah/addad.htm/http://www.angelfire.com/tx (r.11 November Ir) ro

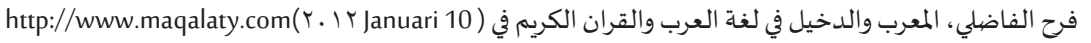

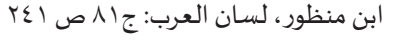


أما مصطلح "الدخيل" اللغوي عند ابن منظور في لسـان العرب، فلا يعدو أن يكون إشـارة

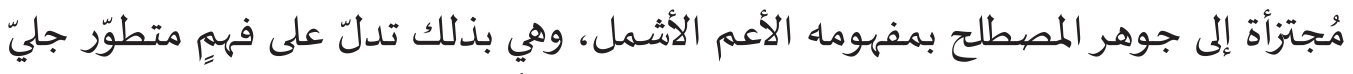

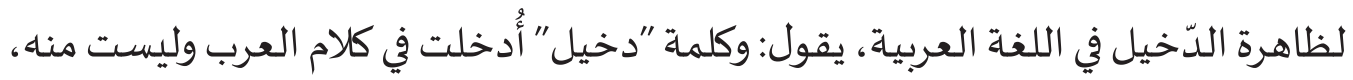

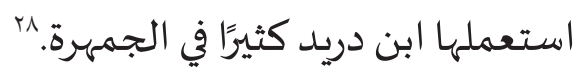

اللغة العربية كما هي باقي اللغات تتبادل التأثروالتأثير، وتُقرض غيرها وتقترض مناه، متى ما اتصل بعضها ببعض، علي أي وجاه وبأي سبب، وتبادل التأثروالتأثير يعد قانوناً اجتماعياً

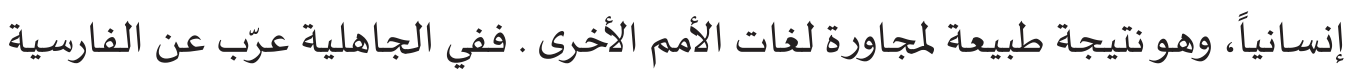

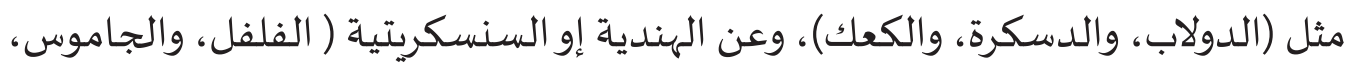

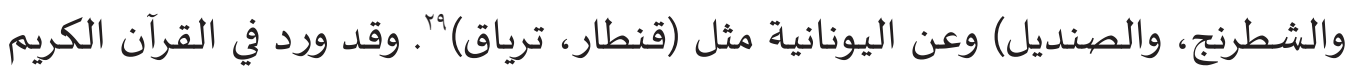

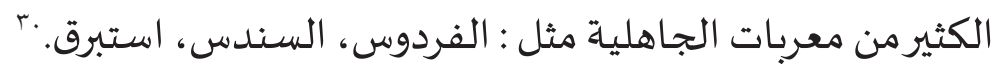

قد عرف الإمام جلال الدين السيوطي المعرب بقوله ((هو ما الستعملته العرب من الألفاظ الموضوعة لمعان في غير لغتها)). ثم نقل السيوطي عن الجوهري في الصحاح قوله ((تعريب الصني

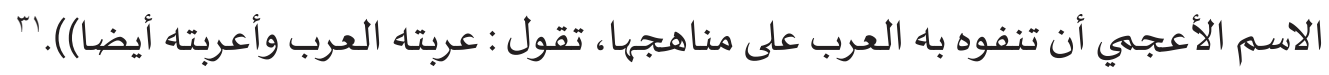
ونوع من الكلمات الأجنبية يعرف بالدخول، وهو دخول الكلمة الأعجمية اللغة العربية

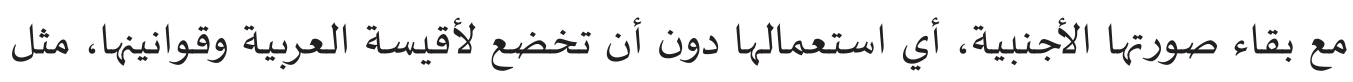

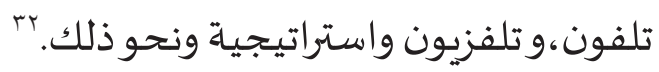

هناك من الأمثلة الكثيرعلى ادعاء العجمة دون بيان الأصل : مثل كلمة الجرداب، وهي تعريب

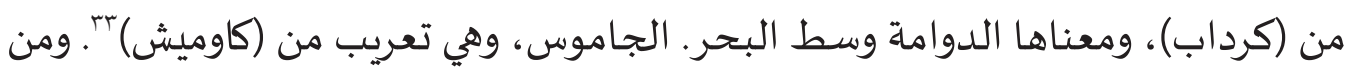

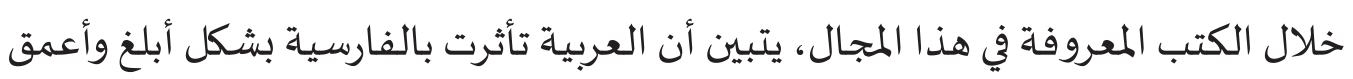

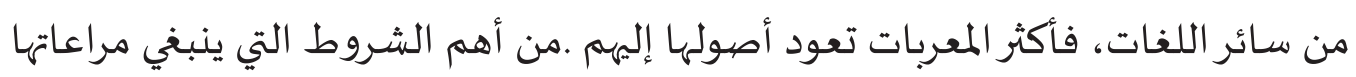

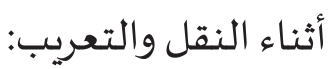

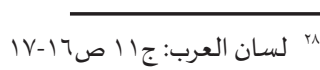

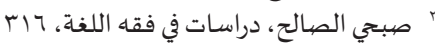

(Y. 1$)$ http://www.almogtama.com/vb/showthread.php?t=10459(15 November

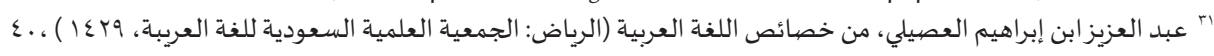

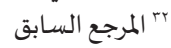

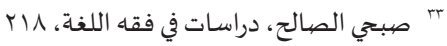


ا. الترجمة الدقيقة التي تقوم مقام التعريب، إذا تحرى الناقل العليم بأسرار العربية،

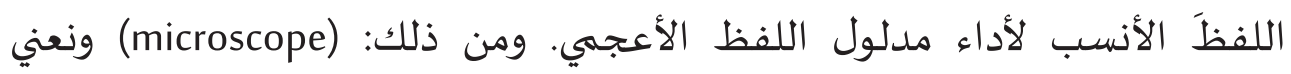
r (المجهار). (1)

r. الكف عن استعمال اللفظ المعرّب إذا كان له اسم في لغة العرب، بهدف إحياء للفصيح وقتلا للدخيل. ومن ذلك : (المَفْذْ) قبل تعريها إلى (باذنجانهان).

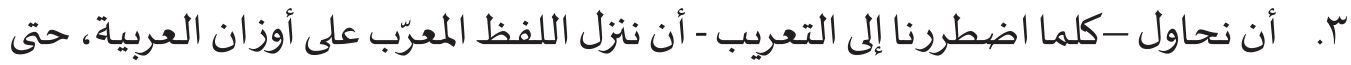

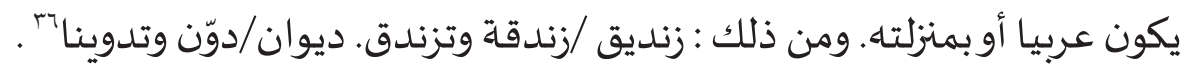
أحيانا لاتكون هناك دقة في التعريب فنضطر إلى إرجاعها إلى تسميتها الأجنبية، مثل (التي ترجمت إلى (علم الطبيعة)، ولكنها ترجمة غير دقيقة، فاستحسن إسلى (physique) استعمالها بلفظ(فيزياء) .كلمة : بريسم ، وزنها مفقود في العربية ـ ولايمكن أن نجد رئد

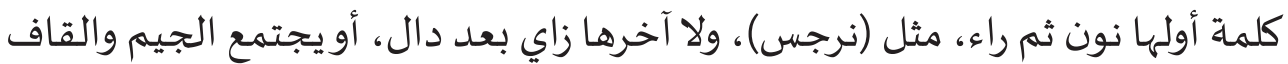

$$
\text { مثل (منجنيق). }
$$

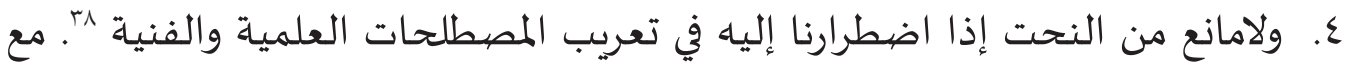
ملاحظة أنها ليس كل مركب ترجم من لفظ أعجمي يثقل في السمع أو يستكره، ولا كل

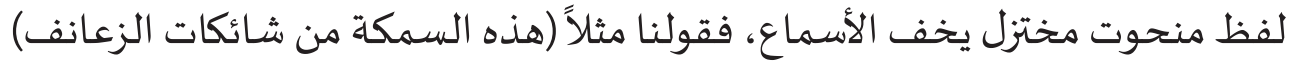
أقرب للفهم من قولنا (شوجنيات)، وقولنا عن (الحشرات) بـ (مستقيمات الاجنحة)

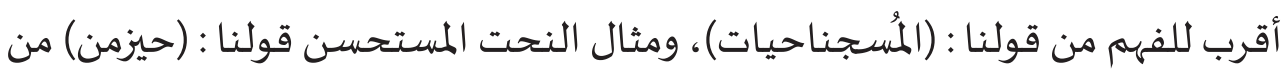

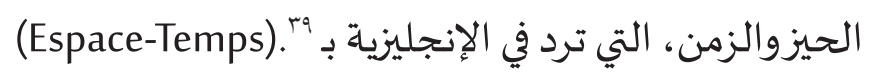

وخلاصة القول أنّ اللغة العربية كما هي باقي اللغات تتبادل التأثروالتأثير، وتُقرض غيرها

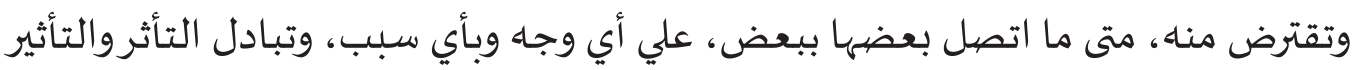

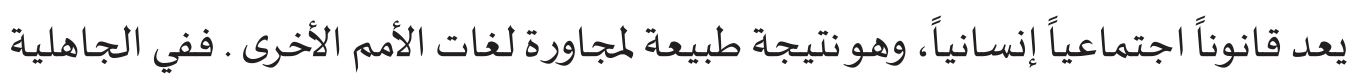

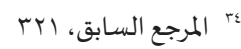
(r. 11 November 10)http://www.almogtama.com/vb/showthread.php?t=1. . ع09 ro

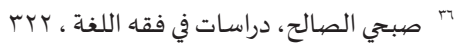
(Y. 11 November 10)http://www.almogtama.com/vb/showthread.php?t=1. . $00^{r r}$

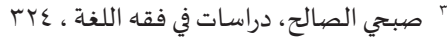

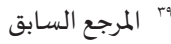


عرّب عن الفارسية مثل (الدولاب، والدسكرة، والكعك)، وعن الهندية إو السنسكريتية ( الفلفل، والجاموس، والشطرنج، والصنديل) وعن اليونانية مثل (قنطار، ترياق).

\section{خلاصة}

بعد أن بحثت الباحثة اتصل الخلاصية :

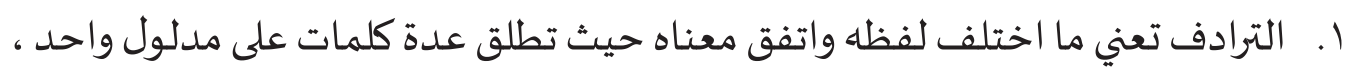

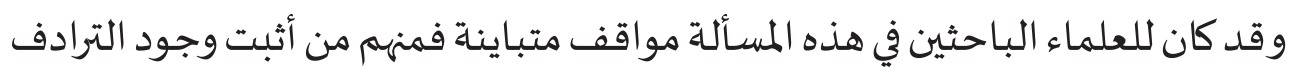

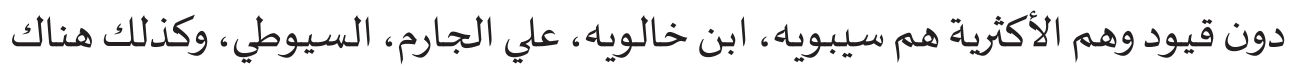

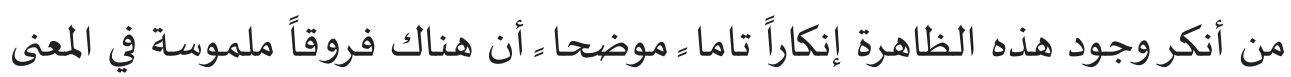

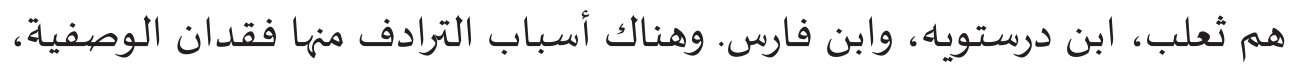

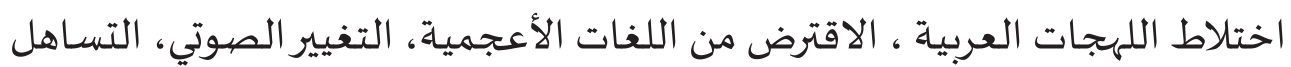

$$
\text { في الاستعمال، و المجاز. }
$$

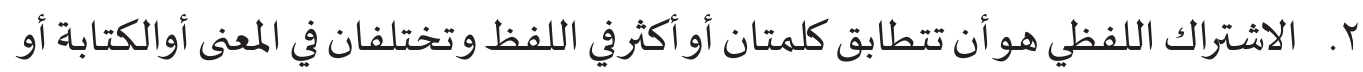

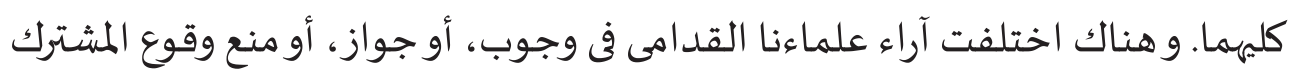

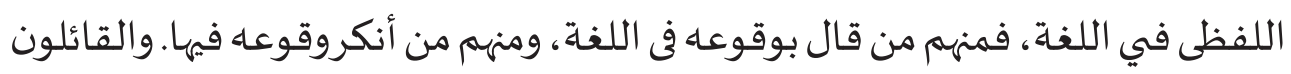

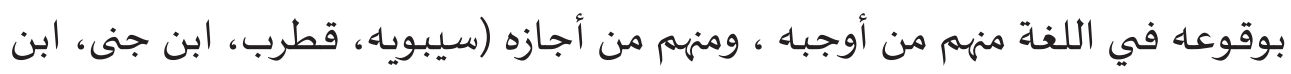

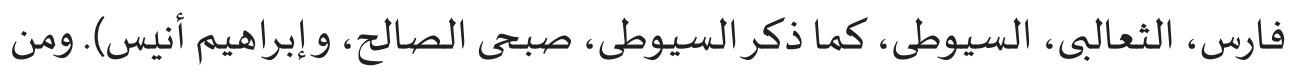

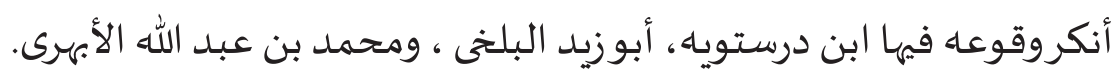

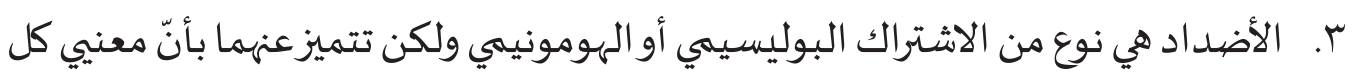

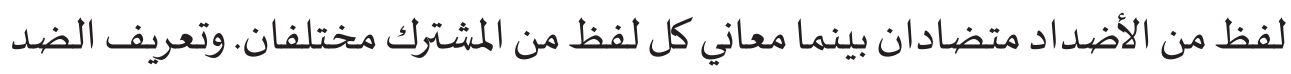

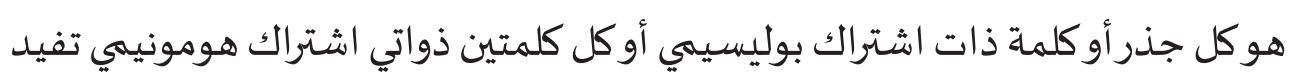

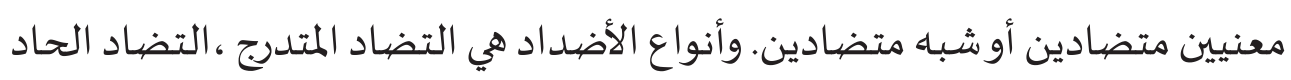

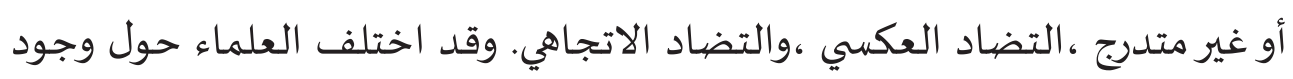

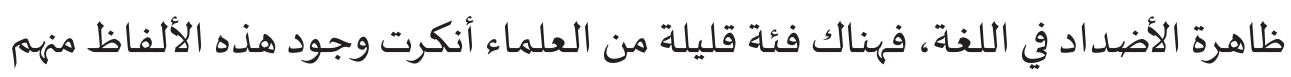

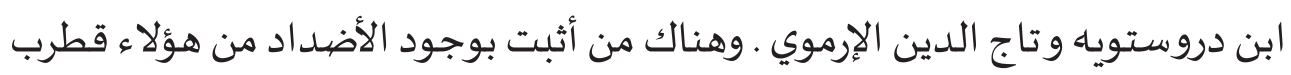


وأبو عبيدة معمر بن المثنى والأصهمعي وابن السكيت والتوزي وأبو حاتم السجستاني وابن دريد والجوهري وابن الأنباري وأبو الطيب اللغوي. ولكن جمهرة علماء العربية يقرون بوجودها في المعجم العربي. وهناك كذلك الاختلاف حول عدد الانباري وألفاظ الأضداد.

\section{المراجع العربية}

أولمان ، ستيفن. 9 و 1 م ـ دور الكلمة في اللغة . ترجمة د. كمال محمد بشر. القاهرة : مكتبة

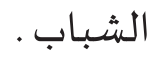

ابن إبراهيم العصيلي. 9r § ا هـ. عبد العزيز. من خصيائص اللغة العربية. الرياض: الجمعية العلمياة السعودية للغة العريبة،،

$$
\begin{aligned}
& \text { ابن منظور، لسان العرب: ج) ـ . } \\
& \text { ، لسـان العرب: لسـان العرب: ج.11 }
\end{aligned}
$$

الخولي، محمد علي ـ ب99 أـ مدخل علم اللغة ـ الأردن: دار الفللاح للنشروالتوزيع . الصالح، صبحي ـ 1977 ـ دراسات في فقه اللغة. بيروت : دار العلم للملايين . العسكري، أبوهلال . ror اهـ. الفروق اللغوية . القاهرة : ط مكتبة القدس.

\section{المراجع الإلكترونية}

المشترك اللفظي عند القدماء والمحدثين في - . المشاء uage/ Y I q \//./\#ixzz liwyK Isbz(9 Januari 2012)

http://www.maqalaty. com ( 10 Januari Y. I T)

معن، مشتاق عباس . فقاه اللغة. لبنان : دار الكتب العلمية ، -.

موسى، محمد ـ المشترك اللفظى في (2http://www.manaratweb.com/print.php?newsid= Irrr (9 Januari 2012) 
http://almenhaj.net/makal.php?linkid= I r) ro. November Y. 11)

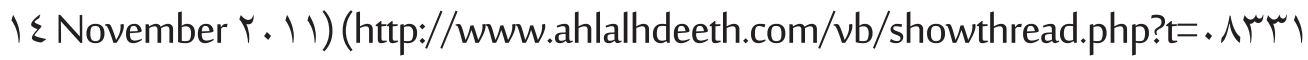

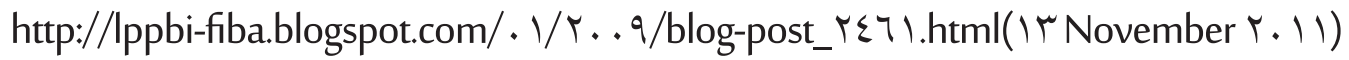

http://www.angelfire.com/tx $\_/$lisan/fiqhlughah/addad.htm(13 November 2011)

http://www.feneks.com/showthread.php?6061-\%C7\%E1\%C3\%D6\%CF\%C7\%CF-

\%DD\%ED-\%C7\%E1\%E1\%DB\%C9(14 November 2011)

http://www.almogtama.com/vb/showthread.php?t=10459(15 November Y. I l)

१ Januari r. I T) (http://www.angelfire.com/tx $\varepsilon /$ lisan/traaduf.htm 